\title{
Banco de dados em pesquisa qualitativa: uma análise a partir da revista $O$ Pequeno Luterano
}

\author{
Patrícia Weiduschadt ${ }^{1}$ \\ Beatriz Teresinha Daudt Fischer ${ }^{2}$
}

\section{Resumo}

0 artigo aborda aspectos operacionais do estudo realizado a partir revista $O$ Pequeno Luterano, impresso dirigido a alunos, professores e pastores das escolas paroquiais no contexto da instituição Sínodo de Missouri (1930-1960). Fundamentando-se em referenciais derivados de Chartier e Certeau, a pesquisa envolveu estratégias de edição, produção e circulação. Aqui, especial ênfase é dada à modalidade de análise escolhida, em especial à categorização do conjunto documental através de um banco de dados adaptado do software denominado e-book. Por meio desse programa pôde-se agrupar os dados em áreas temáticas de acordo com conteúdos ressaltados no impresso, a saber: lúdicos, religiosos e doutrinários; conhecimento secular e de cunho religioso; relação redaçãoleitores; ilustrativos e publicitários. Assim, a análise mostrou que a revista preocupou-se, especialmente, com a religiosidade doutrinária na educação das crianças e, ainda, buscou ser legitimada no espaço escolar através da interlocução com os leitores e nas atividades de conhecimento geral e lúdico que complementavam a formação educacional infantil. As recorrências qualitativas puderam ser percebidas e reafırmadas nas estratégias editoriais, em inúmeros textos abordados com conteúdos religiosos e de formação moral, ao passo que as táticas dos leitores estão manifestas nos conteúdos pouco visíveis na revista, ressaltados pelo descontentamento dos leitores e pelo apelo do editorial ao público infantil a modos específicos de usos e práticas de leitura. Tal ferramenta permitiu verificar objetivamente as recorrências e analisá-las sob rigor epistemológico, potencializando a riqueza do estudo e oportunizando significativa visibilidade à dimensão quali-quantitava dos dados.

\section{Palavras-chave}

História da educação - Impressos - Banco de dados.

1- Universidade Federal de Pelotas, UFPel, RS, Brasil. Contato: prweidus@gmail.com.

2- Universidade do Vale dos Sinos, Unisinos, RS, Brasil. Contato: bea.df@terra.com.br. 


\section{Database for qualitative research: an analysis of The Little Lutheran magazine}

\section{Abstract}

This paper raises operational aspects of the study conducted on 0 Pequeno Luterano (The little Lutheran), a printed brochure intended for students, teachers and pastors from parish schools within the context of the Missouri Synod (from 1930 to 1960). With a line of thought derived from Chartier and Certeau, the research involved strategies of editing, producing and circulating the publication. In this sense, a particular emphasis has been given to the type of analysis chosen, especially the categorization of the set of documents, by using a database adapted from a software called e-book. This software enabled to group data into thematic areas, according to the content highlighted on the brochure, which is divided into: recreational, religious and doctrinal fields, secular and religious knowledge, connection between publishers and readers, as well as graphic and advertising topics. Thus, the analysis showed that the magazine had a special concern about doctrinal religiosity related to childhood education and also pursued to be legitimated by the school community through interaction with readers, in addition to introducing recreational and general knowledge activities in order to support early childhood education. The qualitative recurrences could be perceived and reassured by the magazine's publishing strategies, in several texts addressing religious contents and moral education, whereas the readers' methods were manifest in the magazine's less visible articles, highlighted by their dissatisfaction and the appeal from the editors to encourage reading practices and indicate specific reading use for children. Such tool brought the possibility to objectively verify the recurrences and analyze their epistemological rigor, enhancing the study as well as enabling significant visibility to the qualitative and quantitative dimension of data.

\section{Keyword}

History of education - Printed materials - Databases.

\section{Introdução}

0 estudo de periódicos educacionais mostra-se profícuo para entender práticas educativas e culturas escolares ao longo dos tempos. Tais impressos, marcados por elementos culturais, sociais e ideológicos, quando analisados com o devido rigor metodológico, permitem compreender os propósitos editoriais da instituição a que se vinculam e as características da rede de leitores a que se destinam, bem como determinadas táticas destes diante dos conteúdos a que têm acesso. Dessa forma, possibilitam identificar estratégias desenvolvidas pela instituição editorial na busca de manter e/ou ampliar a circulação do 
periódico. Paralelamente, um processo analítico adequado pode facilitar o reconhecimento de possíveis táticas de que se valem aqueles que colocam os textos e as imagens em circulação. Em sintese, é possivel perceber o projeto educativo que determinadas instituições pretendem instaurar, mesmo quando os leitores não necessariamente se apropriam dos conteúdos conforme estes foram pensados por seus idealizadores. ${ }^{3}$

No campo da História da Educação, são inúmeras as fontes legitimadas para pesquisas com documentos de diferentes naturezas, sejam escritos, orais ou iconográficos. Dentre eles, os impressos parecem ter tido significado relevante nos últimos anos, especialmente os impressos infantis, ou seja, aqueles produzidos para crianças. ${ }^{4}$

0 presente texto deriva de uma pesquisa que analisou a revista $O$ Pequeno Luterano quanto a suas estratégias (CERTEAU, 2011) de edição, produção e circulação (CHARTIER, 2002, 2000, 1996a, 1996b, 1996c), considerando o processo de formação de redes de leitura e de leitores. Trata-se de um impresso dirigido sistematicamente a alunos, professores e pastores da escola paroquial do Sínodo de Missouri, ${ }^{5}$ nas décadas de 1930 a 1960 . Cabe ressaltar que, mesmo não sendo o foco do estudo, as escolas paroquiais do Sínodo de Missouri foram formadas por uma rede coesa. Desde o início da constituição do Sínodo no Brasil destacava-se o fomento da formação das escolas paroquiais com a mesma intensidade em relação à formação das igrejas. Tais escolas foram comunitárias, mantidas pela comunidade local e apoiadas pela instituição religiosa. 0 Sínodo buscou produzir livros didáticos, estimulou a constituição de uma associação de professores. As escolas mantiveram certa estabilidade até o período da nacionalização do ensino (fınal da década de 1930). Depois desse período ocorreu a fragilização das escolas paroquiais, em que a maioria delas se transformou em escolas públicas.

Ao analisar a revista, percebe-se que não foi pensada como material didático de forma sistemática. Foi distribuída na escola paroquial, que não era desvinculada da comunidade. Pode-se inferir que o público escolar a sustentou e a manteve: foi lida pelos alunos e, além disso, os professores estabeleceram uma intensa articulação entre público infantil e editorial. Assim, pode-se observar que o público leitor, em sua grande maioria, era composto de crianças luteranas do Sínodo do Missouri. A maior parte dessas crianças frequentava as escolas paroquiais, mas ainda se podia contar, eventualmente, com a participação de crianças de outras denominações religiosas. No entanto, a revista podia ser assinada individualmente pelas famílias das crianças ou, ainda, a escola podia também ter assinaturas, de modo que a revista era compartilhada pelos alunos. A relação entre a escola e a igreja era estreita, possibilitando efetiva comunicação e convencimento da necessidade de assinaturas.

\footnotetext{
3- Este artigo está baseado em comunicação apresentada em Reunião da Anped pela autora (WEIDUSCHADT, 2015).

4- Os impressos já demonstram relevância e importância nas investigações histórico-educativas, respaldados em estudos de Luca (2010). Ainda em relação aos impressos infantis, cf. Rosa (2002), sobre a revista Tico-Tico; e Bastos (1994), sobre a revista Cacique.

5- 0 Sínodo de Missouri é uma instituição religiosa luterana originária dos Estados Unidos, fundada por imigrantes alemães fugidos do crescente racionalismo religioso no século XVIII na Alemanha. Preza pela ortodoxia e pela confessionalidade luterana. Atualmente é denominada Igreja Evangélica Luterana do Brasil (IELB) (WEIDUSCHADT, 2007).
} 
Esta pesquisa também analisou os processos de planejamento e gerenciamento da revista como dispositivos educacionais e doutrinários. ${ }^{6}$

A revista em questão tornou-se, assim, fonte documental valiosa, gestando instigantes questionamentos. Conforme ressalta Berenice Corsetti (2006, p. 36), as fontes documentais podem ser relevantes, mas o ponto de partida será "a colocação de um questionamento" ou, em outras palavras, de problematizações construídas a partir e em torno de tais fontes. Tendo isso em vista, no presente texto serão abordados alguns dos questionamentos surgidos no processo de investigação da revista $O$ Pequeno Luterano, dando-se especial ênfase à categorização do conjunto documental analisado a partir de um banco de dados adaptado do software denominado E-Book.

\section{Buscando alternativas metodológicas}

A pesquisa foi inicialmente planejada tendo como perspectiva a abordagem qualitativa, considerada mais coerente à análise de impressos no campo da Educação. Entretanto, um desafio foi surgindo: como operar com o conteúdo da revista, tendo em vista a quantidade de páginas e de números publicados, sem perder a riqueza de detalhes? Além disso, a revista possibilitava a imersão em diferentes categorias de análise, que precisavam ser mobilizadas para dar conta da problemática construída. Surgiu, então, a ideia de solucionar tal impasse por meio de um banco de dados. Tal alternativa, embora exigisse operar com aspectos quantitativos, em nenhum momento descartou a dimensão qualitativa da análise. Nesse sentido, as reflexões de Pires (2014, p. 88-89) corroboram o posicionamento aqui assumido:

[...] é possível caracterizar a pesquisa qualitativa pelo emprego de uma técnica particular de dados? Ainda aqui, a resposta é negativa. Podemos fazer observações diretas, entrevistas e análises de documentos, e traduzir todos os nossos resultados em termos quantitativos. [...] Pode-se, então, caracterizar o qualitativo (ou o quantitativo) exclusivamente pela finalidade da pesquisa? Por exemplo, pode-se afirmar que a pesquisa qualitativa serve apenas para descrever ou explorar certos aspectos da realidade, mas que ela é incapaz de explicar ou fornecer provas empíricas, como unicamente pesquisas quantitativas podem fazê-lo? É contra esse preconceito científico que os pesquisadores qualitativos tiveram de se debater desde a retomada das discussões sobre o qualitativo e quantitativo, nos anos 1960. 0 que conta não é o tipo de dados que se utiliza, mas como se constrói a pesquisa.

Ainda que indagações e contrapontos envolvendo dimensões quali-quantitativas tenham surgido em vários estudos e grupos de pesquisa, é possível perceber resquícios de preconceito quanto à escolha de determinados encaminhamentos metodológicos. Neste

6- 0 Sínodo procurou editar impressos para diferentes públicos: tanto infantil, como juvenil e adulto. Além da revista 0 Pequeno Luterano, destinada às crianças, mantinha Jovem Luterano, direcionada aos jovens, e Mensageiro Luterano, para o público adulto, sendo possível perceber a intencionalidade da instituição em fomentar a circulação de determinado impresso para cada segmento geracional. Nesse sentido, a revista aqui em pauta foi editada no intuito de fortalecer a formação educativa e doutrinária das crianças, sendo a escola paroquial o principal difusor da circulação do impresso. 
estudo, acredita-se que, no campo da História da Educação, a abordagem qualitativa não impede a escolha de ferramentas operacionais que permitam olhar o objeto com maior precisão e clareza. Com isso, não se quer dizer que estudos que descartem catalogação de dados quantitativos devam ser desprestigiados. 0 que se argumenta é que, no caso da pesquisa aqui referida, foi determinante encontrar alternativas relacionadas à dimensão quantitativa, a fim de analisar o impresso infantil estudado. Foi a construção desse caminho metodológico, com os cuidados necessários e a leitura atenta dos dados, que favoreceu a potencialização da análise em diferentes aspectos que serão mostrados no decorrer deste texto.

\section{A ferramenta e os procedimentos escolhidos}

Se a análise demanda a problematização dos dados, ao se deparar com grande quantidade de material e conteúdo, os processos de coleta, de seleção, de classificação e de categorização dos impressos são perpassados por dificuldades, já que o trato com esse material não poderá ser meramente descritivo: ele terá de ser analítico. Considerando os 35 anos de publicação da revista $O$ Pequeno Luterano, já a partir de uma leitura inicial do material disponível percebeu-se que muitas Unidades e Subunidades (a serem explicitadas mais adiante neste texto) precisavam ser classificadas e que, de alguma forma, o cruzamento desses dados deveria ser privilegiado. Assim, um banco de dados parecia proporcionar um olhar detalhado e minucioso, contemplando uma forma sistemática de análise. Não há como ocultar que foram trabalhosos tanto os processos da leitura quanto o cadastro de todo o conteúdo do conjunto documental. Entretanto, foi essa organicidade que permitiu um estudo analítico mais efetivo e qualificado.

Para melhor entendimento desse processo, apresentam-se, a seguir, a caracterização e organização da revista e o modo como se constituiu a construção do banco de dados. Posteriormente, serão compartilhados alguns aspectos analíticos desse material, processo facilitado pela categorização e pela possibilidade de cruzamento dos resultados. A metodologia construída por meio do banco de dados possibilitou enfatizar aspectos quantitativos, em especial aqueles de maior recorrência, e, com isso, o objetivo do editorial da revista em relação ao seu público-alvo: as crianças luteranas.

Cabe salientar que os aspectos qualitativos foram selecionados, primordialmente, durante a criação de Unidades Gerais, construídas nas primeiras análises, tendo como fio condutor o conhecimento dos objetivos do impresso, de sua contextualização e de sua vinculação religiosa e ideológica. Só posteriormente foi possível realizar o levantamento das Unidades, que já estavam de certa forma delimitadas antes do cadastramento dos dados. Como se privilegiou o processo, à medida que se classificavam Unidades com grande recorrência, podia-se também perceber Unidades de menor recorrência, mas com grande potencialidade para auxiliar a discussão teórico-metodológica proposta, como os aspectos das táticas (CERTEAU, 2011) dos leitores em burlar determinados preceitos. Nesse sentido, cabe enfatizar que adentrar na discussão do quantitativo e do qualitativo, mais uma vez, parece ser uma falsa questão, pois os cruzamentos do 
número das recorrências com as representações impressas foram fundamentais para enriquecer a pesquisa. ${ }^{7}$

\section{Revista O Pequeno Luterano: fonte e objeto da pesquisa}

A revista $O$ Pequeno Luterano pode ser considerada fonte e objeto, porque apresenta vasto conteúdo significativo, tendo possibilitado, por meio da materialidade dos dados, o fornecimento de pistas para delinear a investigação sobre o processo de educação da instituição responsável pela sua edição. A partir de uma análise quali-quantitativa, é possível afirmar que a composição, o agrupamento, a quantificação e a profundidade no trato com os dados forneceram elementos representativos para o trabalho.

A revista ora analisada surge como documento e como fonte que reforçam e circunscrevem a problemática em questão. Conforme já referido, o uso de impressos como fonte é riquíssimo, pois permite apreender determinados preceitos da produção, da circulação, da edição e da apropriação da rede de leitores que se pretendia formar, a qual é móvel, ou seja, produz apropriações diferentes daquelas previstas pela edição. ${ }^{8}$ É sob essa perspectiva que muitos estudos nos últimos anos têm recorrido à análise de impressos, compondo pesquisas e trabalhos baseados em inúmeras e variadas fontes. ${ }^{9}$

Conforme mencionado, a revista funcionou por 35 anos. Fundada em 1931, circulou até 1939 em língua alemã, sob a denominação de Kinderblatt (Jornal das Crianças). A partir desse ano, com a política de nacionalização do ensino, de Getúlio Vargas, ${ }^{10}$ a publicação passou a ser editada em português, funcionando até 1966 com a denominação de $O$ Pequeno Luterano. Além das edições em menor número de volumes naquele período de repressão, pode-se perceber autorização para a circulação da revista pelo DIP (Departamento de Informação e Propaganda), órgão fiscalizador do Governo Vargas. Outro destaque é a indicação de editor com sobrenome luso, Gastão Tomé (de dezembro de 1945 até junho de 1946), ${ }^{11}$ professor formado pelo seminário pedagógico e que foi responsável pela revista no período de maior fiscalização.

7- Muito se tem discutido a respeito da falsa contradição entre a importância dos aspectos quantitativos e qualitativos, porém, segundo Gamboa e Santos Filho (2002), mais que valorizar um aspecto ou outro (quantidade-qualidade), é preciso buscar problematizar a pesquisa, utilizando as diferentes abordagens.

8- Nesta discussão, estamos nos apoiando em conceitos de Chartier (2002, 2000, 1996a, 1996b).

9 - Na esteira analítica do uso de fontes variadas, em especial dos impressos que podem ser fonte e objeto, os estudos da História Cultural têm auxiliado e ampliado o campo investigativo nos últimos anos (PESAVENTO, 2004). Pode-se citar como exemplos os trabalhos de Biccas (2008) e de Fischer (2005), entre outros de relevância no meio acadêmico.

10 - A política de nacionalização do Governo Vargas teve como alvo a centralização do ensino. As escolas de imigração sofreram repressão, proibiu-se a língua alemã no espaço escolar, nas igrejas e na imprensa, bem como nas esferas religiosa e educativa das comunidades étnicas, a partir do final da década de 1930 (SCHWARTZMAN; BOMENY; COSTA, 1984).

11- A revista passou por dez editores ao longo de sua circulação, sendo todos homens e formados pastores ou professores do Sínodo de Missouri. Os redatores mantinham contatos com os leitores, liam as cartas e organizavam o conteúdo da revista, mas não tinham dedicação exclusiva como redatores. Em geral, acumulavam a função com o exercício do magistério ou eclesiástico. 
Figura 1 - Imagem da primeira edição encontrada, ainda denominada Kinderblatt (à esquerda); imagem da capa da primeira edição em português da revista 0 Pequeno Luterano (à direita).

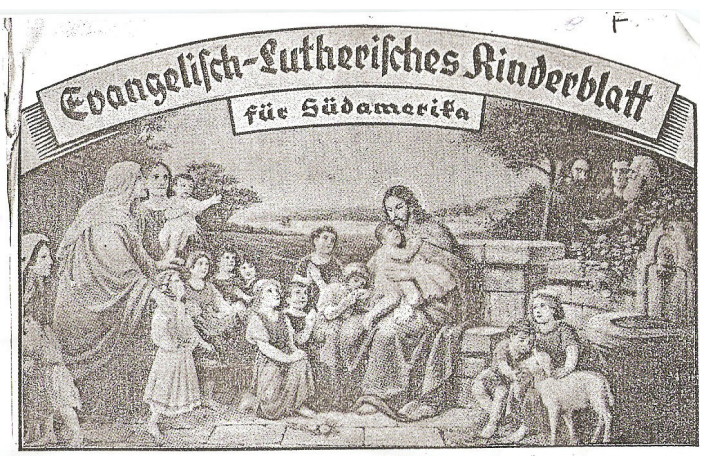

1. Iafrint.

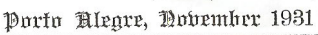

321. 11

Stitrm auf tom 10inere. Marf. 4, 35-39.

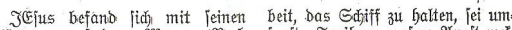

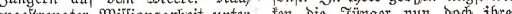

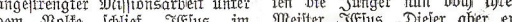

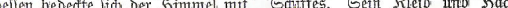

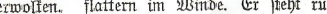

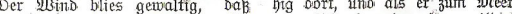

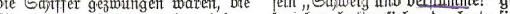

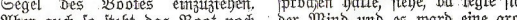
aber aut po Hejt bas bot hos ber The elt turzen ins boot, die rude Gaben fid gewis bei ber Orrbeit angelfrengt, um bas Sdinf zu bals telt. Wher jegt babent fic bie 50 fif rullg perloretl. (Einer Don Den Jütigerti, es wixo mahnidgeinlid Ien, wenn fie lif erbeben", $\mathfrak{B}$

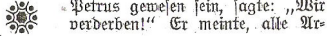
ten fidjer ants Iffer! mit bem

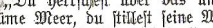
9,10 .

Fonte: Revista O Pequeno Luterano (1931 e 1939).
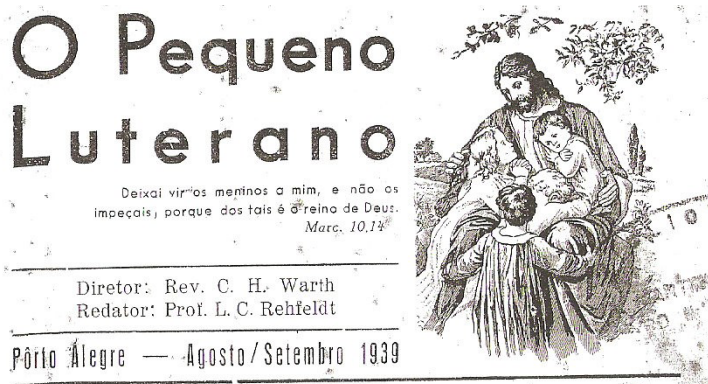

\section{Jesús ama os memimos}

Marc. $10,23-16$

Jesús, o nosso Salvador, ama os meninos. Isto sabeis da Bíblia. Quando uma vez os discipulos perguntaram: «Quem é a mator no rênto dos céus?» Jesús respondeu claramente chamatido um menino: «Em verdada vos digo que se não vos converterdes e năo vos fizerdes como meninos, de modo algum entrareis no reino dos céus. Portanto, aquele que se tornar humilde como êste menino, êsse é o maior no reino dos céus. - Si olhardes para a estampa na segunda página, vereis seis theninos, alegres e contentes. Fazem, como vós muitas vêzes o fazeis, quando reunidos ent̂ vossos brinquedos cantais os hinos, que aprendestes da vossa bôa mãi ou do vosso nprofessor na escola. Vedes a alegria no rosto destes seis meMinos? Eles de certo o sabem, que têm um Salvador, que os' anta. Eles cantam hinos e fazem música em instrumentos simples $e^{*}$ improvisos que fizeram com suas próprias mãos. Assirn também vós sois alegres e contentes, sabendo que Jesús também ama a vós. Amais o bom Pastor e sois cordeiros de Jesús. Quereis agradar a êle? Então fazei o que diz o apóstolo Paulo aos Colossenses: «A palavra de Cristo habite em vós

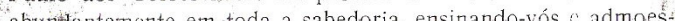

Diante de um material denso e de conteúdo significativo (em termos quantitativos, a revista apresenta extenso número de edições e de páginas em cada publicação), a tabela a seguir, dividida por décadas, apresenta um panorama geral das edições.

Tabela 1 - Apresentação numérica das edições e do número de páginas.

\begin{tabular}{c|c:c}
\hline Período & Número de edições & Número de páginas \\
\hline 1931-1939 (Kinderblatt) & 60 & 272 \\
\hline 1939-1949 (O Pequeno Luterano) & 85 & 501 \\
\hline $1951-1959$ (O Pequeno Luterano) & 73 & 784 \\
\hline 1960-1966 (O Pequeno Luterano) & 59 & 782 \\
\hline Total & 277 & 2.339 \\
\hline
\end{tabular}

Fonte: Dados da pesquisa 
As edições da revista eram, geralmente, mensais, embora muitas circulassem bimestralmente, em especial nos meses de janeiro e fevereiro, período de férias escolares. Em momentos de crise, apresentavam pouca circulação. Na década de 1940, por exemplo, especificamente em 1945 e 1946, são editados, respectivamente, quatro e cinco números, demonstrando as dificuldades encontradas no período de nacionalização do ensino. Ao longo desta investigação, teve-se acesso a quase toda a coleção, com exceção dos números dos anos de 1934 e 1935 e de alguns exemplares do ano de 1953. Observando-se as edições, é possível perceber o aumento quantitativo do material impresso, com crescente número de páginas da revista a cada década de sua circulação.

De 1931 até 1948, a edição somava 48 páginas anualmente. Quando a revista apresentava publicação bimestral, o número de páginas aumentava proporcionalmente. Desde 1949, houve um aumento significativo de páginas, variando, em média, entre 50 e 136 páginas a cada ano. Desse período, estão disponíveis para análise todas as edições, com exceção dos meses de setembro a dezembro de 1953. Conforme indicado na Tabela 1, o conjunto do acervo investigado compreendeu 277 periódicos, totalizando 2.339 páginas.

Nota-se, ainda, que a circulação da revista era relativamente intensa. Na década de 1950, os dados apontam para 1.200 assinantes; em 1962, a tiragem era de 1.400 exemplares, mas a média das assinaturas dos leitores fixos girava em torno de 1.162. Em 1964, o aumento da tiragem é visível, passando para 1.600 assinantes. Essa discrepância entre a tiragem e o número de assinantes na década de 1960 deve-se, em grande parte, ao patrocínio recebido pela revista e à maior mobilidade de circulação para além dos assinantes. ${ }^{12}$

\section{Organização dos dados constituídos}

Ao deparar-se com grande quantidade e riqueza de material para análise, é preciso definir formas objetivas de tratamento. 0 primeiro contato com a revista ocorreu na biblioteca do Seminário Teológico Concórdia, ${ }^{13}$ caracterizando-se por um breve olhar por toda a coleção. Muitos dados eram apresentados ali: a revista escrita em alemão e sua transição ao português, a interlocução com os leitores, os textos doutrinários etc. Não haveria a possibilidade de realizar uma seleção sem que houvesse uma imersão no material para delinear alguns pontos. Diante disso, solicitaram-se fotocópias de toda a coleção, as quais foram concedidas prontamente. De posse das fontes, foi dado início ao trabalho de leitura e aos ensaios de análise.

Depois de eleger a revista em questão como foco da pesquisa, as leituras realizadas de forma minuciosa evidenciavam a dificuldade que traria o processo analítico. Foi então que, conforme já anunciado, surgiu a necessidade de elaborar um banco de dados. Outros trabalhos no campo da História da Educação já propuseram a construção de um banco de dados que pudessem subsidiar o processo analítico de impressos. ${ }^{14}$

12- Nem sempre são exatos os dados sobre tiragens e assinaturas. 0 acesso ao número de assinantes e tiragens consta no próprio jornal, a partir da década de 1950. Nesse período há significativo aumento de patrocínio, então se pode inferir que a diferença entre assinantes e tiragem deve-se, em grande parte, ao patrocínio recebido pela revista e à maior mobilidade de circulação para além dos assinantes.

13- Seminário vinculado à IELB, localizado em São Leopoldo. Em anexo, encontra-se a biblioteca do curso de Teologia da IELB.

14- Este estudo se inspirou no trabalho de Kuhlmann Júnior e Fernandes (2008), que tem como fonte principal um impresso. Os autores utilizam, em sua pesquisa, o software livre WINISIS, um modelo de dados difundido pela Organização das Nações Unidas para a Educação, a Ciência e a Cultura (Unesco). 
Em um primeiro momento, foi realizada uma leitura geral de todos os números disponibilizados da revista, a fim de verificar os principais enunciados e eleger as Unidades significativas de análise. ${ }^{15} \mathrm{O}$ banco de dados utilizado foi o programa E-Book, um software livre usado por bibliotecários para a catalogação de livros, sendo necessárias adaptações para atingir os objetivos específicos deste estudo.

Para melhor compreensão do uso desse programa, são apresentadas, a seguir, algumas caixas de diálogo e o modo de operacionalização do programa. Ao abrir o programa, visualizam-se modos de cadastro das informações. 0 programa apresenta uma ferramenta denominada Adicionar Livro, local escolhido para inserir o texto da revista. Assim, abria-se uma caixa como a apresentada a seguir:

Figura 2 - Caixa do banco de dados.

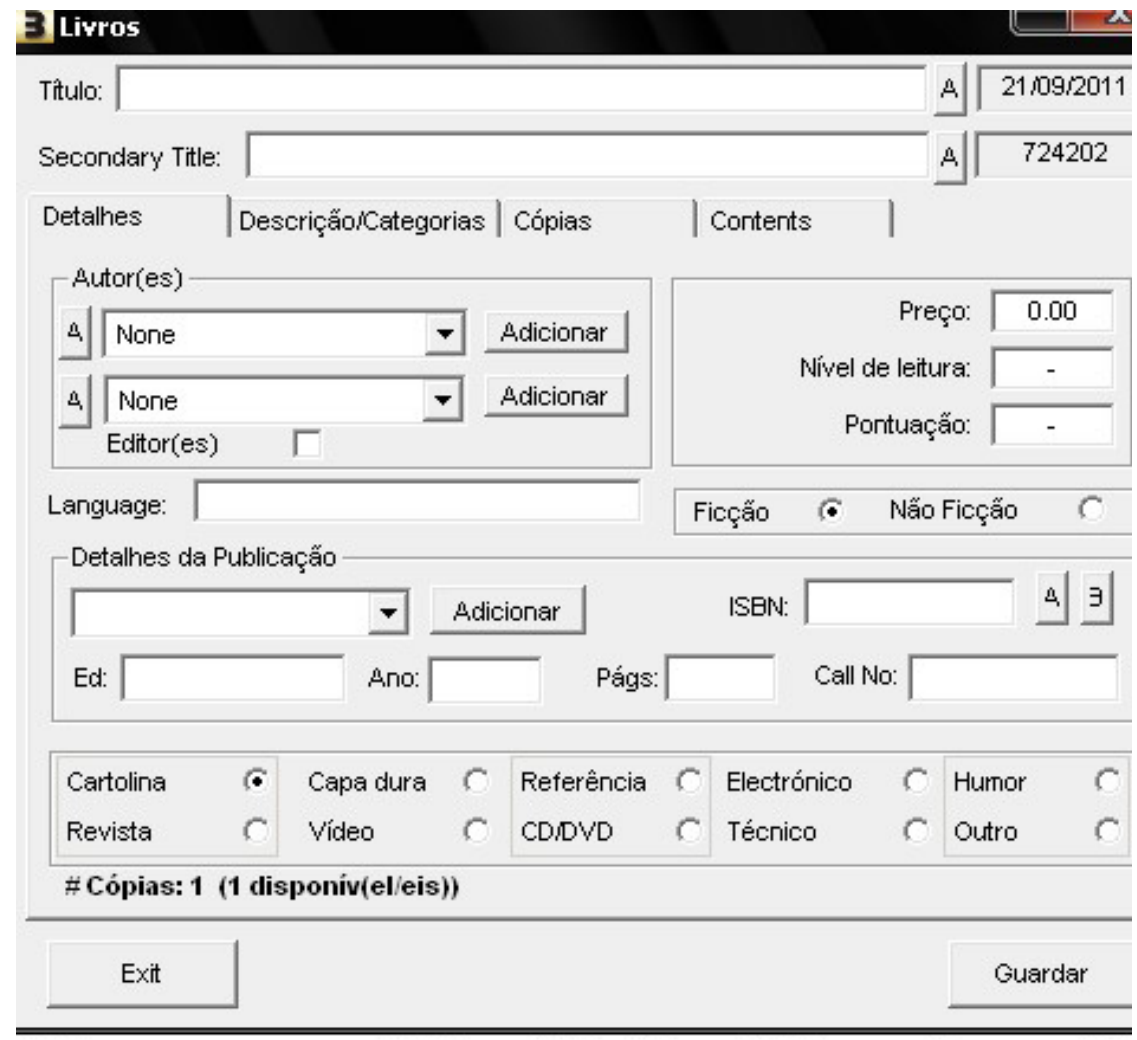

Fonte: Banco de dados organizado pelos autores.

15- Destaca-se que seria relevante aprofundar, neste trabalho, aspectos formais da estrutura da revista e espaços em que constavam os diferentes tipos ou gêneros de leitura, mas não será possível essa análise com maior profundidade por não ser o foco central da operacionalização do banco de dados. Apenas para ilustrar, percebeu-se que os conteúdos de maior recorrência eram apresentados no início do periódico e os conteúdos lúdicos e publicitários na última página. Percebe-se que a disposição gráfica escolhida pelos editores era organizada de forma hierárquica em relação aos conteúdos por eles considerados mais úteis aos leitores. 
No espaço denominado Título, anotava-se a Unidade construída, e, no espaço denominado Subtitulo, anotava-se o título do texto da revista. Esses foram considerados na caixa denominada Detalhes, em que aparecia espaço para identificar o autor, no qual foi colocado o nome do autor ou dos autores do texto. Quando o texto não estava assinado, optou-se por utilizar a expressão $A$ redação. Para efetuar o cadastramento, na caixa Detalhes da Publicação precisava constar obrigatoriamente um item. Então, optou-se pelo nome da revista, sendo escrito em português (O Pequeno Luterano) ou em alemão (Kinderblatt), conforme a língua utilizada em cada edição. Na caixa abaixo (Ed, Ano, Pags e Call $N o$ ) e na caixa ao lado direito $(I S B N)$, criaram-se correlatos: $E d=$ número do mês correspondente; $A n o$ = ano da revista; Call No = número do ano da edição; e $I S B N=$ meses da edição. A seguir, pode-se observar um exemplo de caixa de dados já cadastrados:

Figura 3 - Caixa de banco de dados completa.

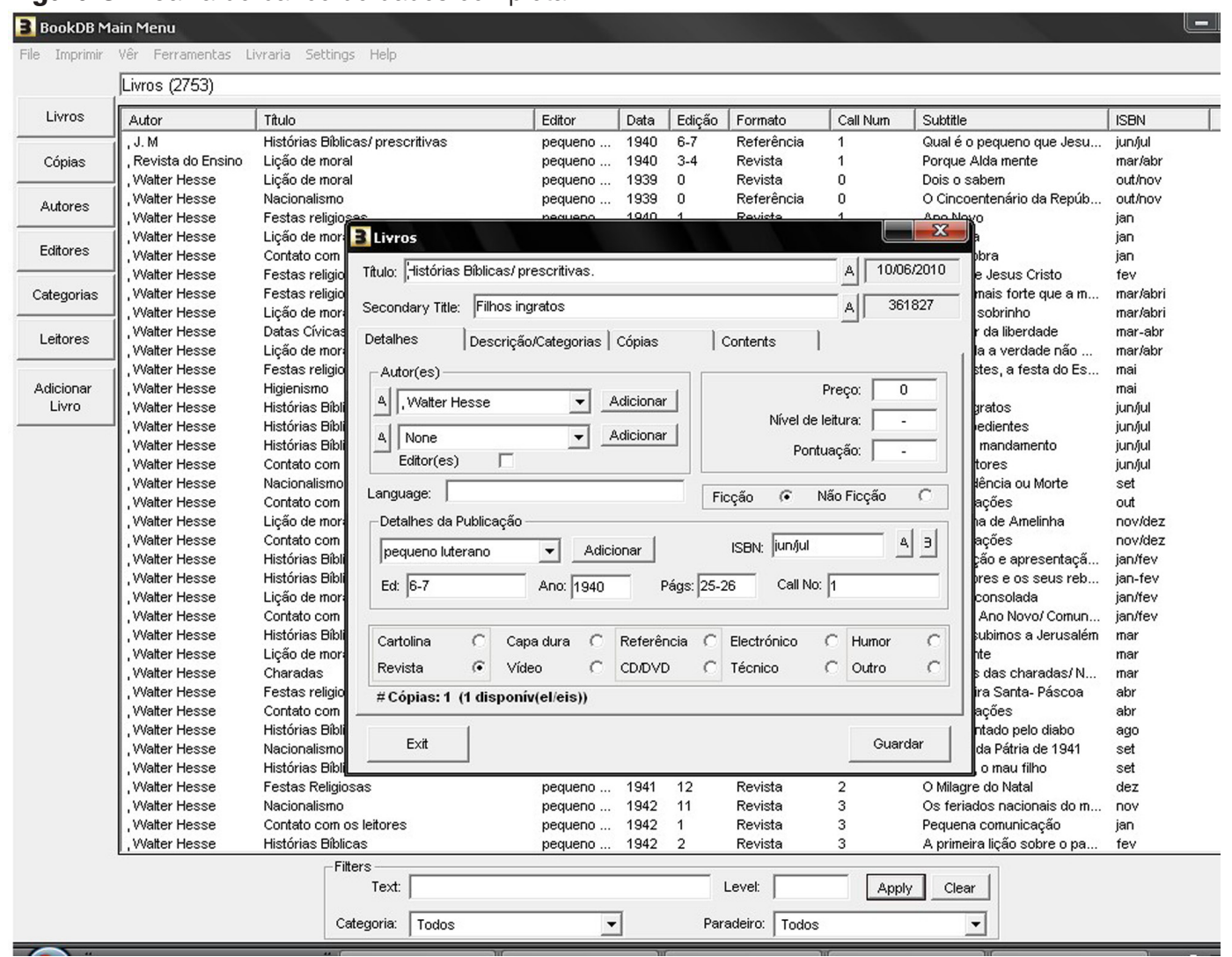

Fonte: Banco de dados organizado pelos autores.

No exemplo apresentado na Figura 4, no campo destinado ao título, consta Histórias Bíblicas/ prescritivas, denominando uma Unidade construída. No subtítulo, aparece o título do texto da revista Filhos Ingratos, da autoria de Walter Hesse (cadastrado como Pequeno luterano, Ed: 6-7, Ano: 1940, p. 25-26; Cal No: 1 e ISBN: jun./jul., já que 
1940 foi considerado o ano 1 da revista em português - como esse título foi publicado em junho/julho, o Call No corresponde ao número 1). Depois de acrescentar os detalhes, o programa direciona ao item Descrição/Categorias, em que se abre outra janela, mas a partir do mesmo título, como pode ser percebido na Figura 4, apresentada a seguir.

Figura 4 - Caixa de dados com apresentação do item Descrição/Categorias.

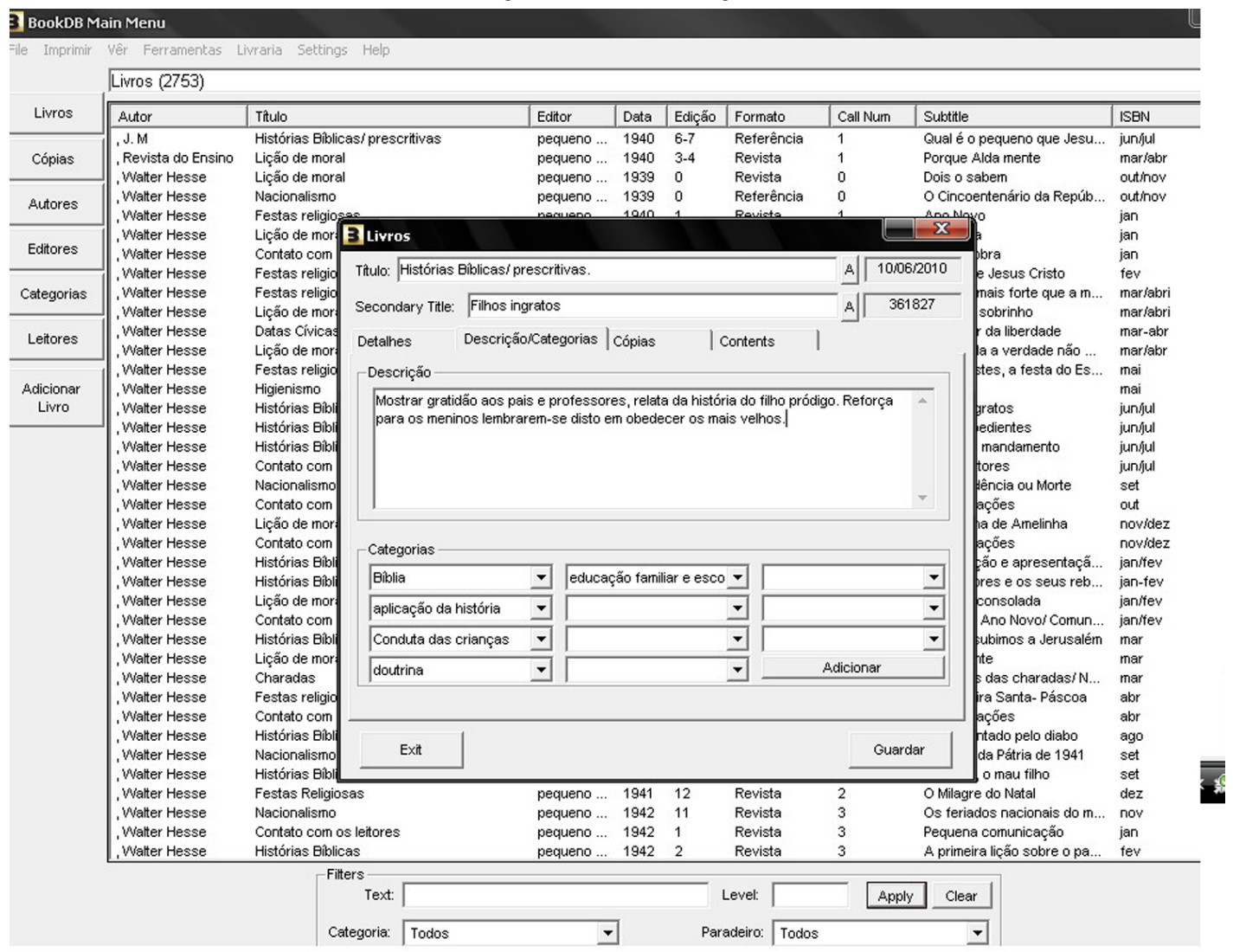

Fonte: Banco de dados organizado pelos autores.

Na Descrição, foi cadastrado um breve resumo do texto e, em Categorias, construíram-se diferentes Subunidades, permitindo analisar o que seria mais recorrente. Também foi possivel acrescentar novas Subunidades (no programa que se chama Categorias), por meio do comando Adicionar, para que tais Subunidades pudessem ser cruzadas com as Unidades Gerais. As outras janelas foram desconsideradas, pois são de uso do programa da biblioteca, não figurando como necessárias para esta análise. Por fim, a janela Guardar permitia salvar o que estava sendo trabalhado.

Seguindo os procedimentos descritos, todos os títulos dos textos da revista foram colocados nessa base de dados, mesmo os textos que eram formados por apenas uma imagem, ação que facilitou a pesquisa, o trato dos dados e os possíveis cruzamentos. 
Nessa fase de constituição da base de dados, já houve um processo de análise preliminar, ${ }^{16}$ uma vez que, no decorrer dos registros, construíram-se Unidades Gerais e Subunidades, à medida que os textos iam sendo organizados.

Dessa forma, a organização do banco de dados facilitou enormemente os encaminhamentos de análise, uma vez que os registros puderam ser selecionados de acordo com critérios diversos (ano da edição, autor e assuntos das Unidades e Subunidades, por exemplo), além de permitir cruzar os dados de determinada Unidade com a Subunidade escolhida. Assim, por meio da descrição do texto, foi possível identificar os conteúdos que teriam mais potencialidade analítica sob determinada perspectiva.

$\mathrm{Na}$ aba Título, foram colocadas as Unidades Gerais construídas a partir das recorrências encontradas no conteúdo da revista. Ao todo, foram analisados 2.753 títulos, incluindo imagens e capas. Em resumo, a revista foi lida e analisada detalhadamente. Assim, no decorrer da análise e de acordo com a leitura e a perspectiva dos temas, foram elencadas as seguintes Unidades Gerais, apresentadas a seguir em ordem alfabética:

Tabela 3 - Unidades e recorrência.

\begin{tabular}{|c|c|}
\hline Unidades gerais & Quantidade de recorrência \\
\hline 1- Adivinhações & 49 \\
\hline 2-Anúncios & 60 \\
\hline 3- Brincadeiras na escola & 14 \\
\hline 4- Charadas & 198 \\
\hline 5- Conhecimento geral & 232 \\
\hline 6- Contato leitor-revista & 207 \\
\hline 7- Datas cívicas & 70 \\
\hline 8- Escolas paroquiais & 24 \\
\hline 9- Festas religiosas & 255 \\
\hline 10- Higienismo & 59 (33 assinados pelo SNES) $^{*}$ \\
\hline 11- Histórias em quadrinhos & 13 \\
\hline 12- Histórias bíblicas & 275 \\
\hline 13- Imagem & 338 (165 somente a imagem) \\
\hline 14- Lição de moral & 742 \\
\hline 15- Nacionalismo & 95 \\
\hline 16- Notícias da igreja & 25 \\
\hline 17- Piadas & 86 \\
\hline 18- Redação da revista & 6 \\
\hline
\end{tabular}

Fonte: Banco de dados organizado pelos autores.

* Sigla que significa Serviço Nacional de Educação Sanitária

16- Conforme Kuhlmann Júnior e Fernandes (2008, p. 17), em seu sugestivo trabalho já citado: "Considerando esta Base de Dados, pode-se afirmar que a sua produção já se constituiu em um primeiro processo de análise da publicação, na medida em que exigiu o esforço para interpretar as informações que comporiam os dados". 
Depois que as Unidades gerais foram construídas e relacionadas, procedeu-se ao agrupamento em temáticas comuns, por meio da operacionalidade do banco de dados (conforme Tabela 4).

Tabela 4 - Agrupamento temático das Unidades e do número de recorrências.

\begin{tabular}{|c|c|c|}
\hline Agrupamento temático & Unidades relacionadas & Número de recorrências \\
\hline Conteúdos lúdicos & $\begin{array}{l}\text { Adivinhações } \\
\text { Brincadeiras na escola } \\
\text { Charadas } \\
\text { Histórias em quadrinhos } \\
\text { Piadas }\end{array}$ & 360 \\
\hline Conteúdos religiosos e doutrinários & $\begin{array}{l}\text { Festas religiosas } \\
\text { Histórias bíblicas } \\
\text { Lição de moral }\end{array}$ & 1272 \\
\hline Conteúdos de conhecimento secular e de cunho ideológico & $\begin{array}{l}\text { Conhecimento geral } \\
\text { Datas cívicas } \\
\text { Higienismo } \\
\text { Nacionalismo }\end{array}$ & 456 \\
\hline Conteúdos sobre a relação redação-leitores & $\begin{array}{l}\text { Contato leitor-revista } \\
\text { Escolas paroquiais } \\
\text { Notícias da igreja } \\
\text { Redação da revista }\end{array}$ & 262 \\
\hline Conteúdos ilustrativos e publicitários & $\begin{array}{l}\text { Anúncios } \\
\text { Imagem }\end{array}$ & 398 \\
\hline
\end{tabular}

Fonte: Banco de dados organizado pelos autores.

Em relação às Subunidades, conforme apresentado na Tabela 5, elas poderiam ser acrescentadas, para que, logo em seguida, fosse feito o cruzamento. Assim, foram construídas 52 Subunidades, o que permitiu identificar as de maior recorrência no agrupamento temático.

Tabela 5 - Agrupamento das Subunidades em áreas temáticas.

\begin{tabular}{|c|c|c|c|c|}
\hline Conteúdos lúdicos & $\begin{array}{l}\text { Conteúdos religiosos e } \\
\text { doutrinários }\end{array}$ & $\begin{array}{l}\text { Conteúdos de conhecimento } \\
\text { secular e de cunho ideológico }\end{array}$ & $\begin{array}{l}\text { Conteúdos sobre a relação } \\
\text { redação-leitor }\end{array}$ & $\begin{array}{c}\text { Conteúdos ilustrativos e } \\
\text { publicitários }\end{array}$ \\
\hline $\begin{array}{c}\text { Aplicação da história } \\
\text { Conduta das crianças } \\
\text { Texto lúdico } \\
\text { Curiosidades }\end{array}$ & $\begin{array}{c}\text { Aplicação da história } \\
\text { Conduta das crianças } \\
\text { Dirige-se ao leitor } \\
\text { Virtudes } \\
\text { Bíblia } \\
\text { Confiança em Deus } \\
\text { Doutrina } \\
\text { Luteranismo } \\
\text { Assistencialismo } \\
\text { Biografia } \\
\text { Conversão } \\
\text { Bucolismo } \\
\text { Indicação de versículos } \\
\text { Missão } \\
\text { Conduta de jovens } \\
\text { Conformismo } \\
\text { Órfãos } \\
\text { Superstição } \\
\text { Música }\end{array}$ & $\begin{array}{c}\text { Aplicação da história } \\
\text { Conduta das crianças } \\
\text { Alerta de doenças } \\
\text { Ciências } \\
\text { Civismo } \\
\text { Exaltação de Vargas } \\
\text { História factual } \\
\text { Higienismo } \\
\text { Português } \\
\text { Textos explicativos } \\
\text { Ufanismo } \\
\text { Geografia } \\
\text { Poesia } \\
\text { Desenvolvimentismo } \\
\text { Eurocentrismo } \\
\text { Gaúcho } \\
\text { Matemática } \\
\text { Maternidade } \\
\text { Obediência } \\
\text { Política } \\
\text { Trabalho }\end{array}$ & $\begin{array}{c}\text { Aplicação da história } \\
\text { Conduta das crianças } \\
\text { Educação familiar e escolar } \\
\text { Escolas paroquiais } \\
\text { Atividades escolares } \\
\text { Estímulo à leitura } \\
\text { Controle da leitura } \\
\text { Escola dominical } \\
\text { Reclamações/pedidos } \\
\text { Dinheiro e religião } \\
\text { Pomeranos } \\
\text { Publicidade }\end{array}$ & $\begin{array}{l}\text { Aplicação da história } \\
\text { Conduta das crianças } \\
\text { Imagens } \\
\text { Capa }\end{array}$ \\
\hline
\end{tabular}

Fonte: Banco de dados organizado pelos autores. 
A partir desse agrupamento em Subunidades, pode-se visualizar o projeto da revista, chamando atenção o fato de que duas delas, denominadas Aplicação da história e Conduta das crianças, estão presentes em todos os conteúdos ou nas chamadas áreas temáticas. ${ }^{17}$

Com base em uma análise geral, pode-se inferir que o projeto para educar por meio da revista incidia nas formas com que a redação aplicava a moral da história, tanto as de cunho moral e religioso, quanto as de conhecimento secular. Ao mesmo tempo, a interlocução, a ludicidade e a publicidade serviam quase sempre à busca da aplicabilidade e da utilidade, visando à formação da criança.

Tais aspectos, de certa forma, representam o projeto educacional pretendido pela revista: a formação da criança para o futuro como fiel da Igreja. Tendo sido uma das estratégias mais utilizadas pela revista, poder-se-ia intuir que o leitor fosse conduzido, ou seja, totalmente capturado por essa intenção. Entretanto, ele de fato se apropria de diferentes formas das leituras que lhes são apresentadas, utilizando-se de táticas escapatórias. ${ }^{18}$ Nas palavras de Certeau (2011), o leitor tem certa autonomia em pinçar e/ ou caçar a mensagem que lhe faz sentido. ${ }^{19}$

Entretanto, a temática de menor recorrência foi a de Conteúdos da relação redatorleitor, agrupamento em que muitas Subunidades tiveram pouquíssimas recorrências, como a de Estímulo e Controle da leitura e a de Reclamações/pedidos. Observaram-se, assim, dificuldades da redação da revista em manter o seu público como leitor e, mais ainda, em permitir a manutenção dos modos de ser leitor. As táticas dos leitores em burlar os propósitos que o editorial manifesta são colocadas em evidência a partir de poucas recorrências. São os escapes a que Certeau se refere.

Considerando a dimensão qualitativa de análise, o agrupamento temático com um número inexpressivo de recorrência também foi tratado com cuidado e profundidade. É necessário chamar a atenção, entretanto, para o fato de essas Unidades serem construídas a partir do olhar do pesquisador no trato com os dados e com os aspectos mais significativos do estudo, carregando traços subjetivos, mas nem por isso deixando de ter relevância e pertinência.

\section{Uso nas escolas paroquiais e formação moral do leitor}

Pode-se perceber que a revista era direcionada ao público infantil. Como se investia muito na formação das crianças no meio institucional do Sínodo de Missouri, ${ }^{20}$ os conteúdos apresentados na revista estavam de acordo com as propostas doutrinárias da referida instituição.

17- Conforme se apresentou na Tabela 5, foi possível construir 52 Subunidades; e, como consta na Tabela 4, foram construídas 18 Unidades. No texto integral da tese, esse cruzamento é apresentado de forma detalhada (WEIDUSCHADT, 2012). Para melhor esclarecimento, as denominadas Aplicação da história e Conduta de crianças perpassaram todo o material, conforme consta na Tabela 5. Elas foram assim denominadas porque os textos incidiam na aplicabilidade da história no cotidiano das crianças a fim de estas refletirem sobre os conteúdos apresentados, sobre como deveriam aplicá-los em sua vida e controlar sua conduta. A revista não serviria apenas para entretenimento e distração, mas deveria influenciar a conduta dos leitores para se tornarem bons alunos/leitores/cristãos.

18- Nesse sentido, foram usados os conceitos de Chartier (1992) sobre a apropriação. Cada leitor pode ser estimulado a determinado interesse de leitura, desenvolvendo aptidões e expectativas em relação à leitura, mas irá imprimir um sentido próprio, de acordo com as suas experiências sociais. 19 - "Se, portanto, o livro é um efeito (uma construção do leitor), deve-se considerar a operação deste último como uma espécie de léctio, produção própria do leitor. Este não toma o lugar de autor nem um lugar de autor. Inventa nos textos outra coisa que não aquilo que era a 'intenção' deles" (CERTEAU, 2011, p. 241, grifo do autor).

20- 0 Sínodo de Missouri, desde a sua fundação, investiu em escolas paroquiais e na formação de docentes qualificados. Muitos dos editores da revista eram professores formados no seminário pedagógico. Para saber mais, ver Weiduschadt (2007). 
Conforme referendado anteriormente, na Tabela 5, as temáticas levantadas no banco de dados foram compostas de elementos lúdicos, propícios ao período da infância; conteúdos religiosos e doutrinários, direcionados à formação das crianças; e conhecimento secular e ideológico, já que as crianças precisavam da educação geral. Também se fez presente a relação entre a redação e os leitores, em virtude da necessidade de interlocução para a própria manutenção da circulação do impresso. Além disso, percebe-se que, na composição do impresso, há relativo material ilustrativo e publicitário direcionado a crianças e adultos (professores e pastores das escolas paroquiais).

Sem dúvida, a temática de maior recorrência diz respeito a conteúdos religiosos e doutrinários, abordando Histórias bíblicas, histórias de Lição de moral e histórias que reforçam a comemoração das Festas religiosas. Essas três Unidades permitem perceber o cabedal de conteúdos que serviriam à formação e à projeção do aluno/fiel/leitor no futuro, ainda mais quando cruzadas com as Subunidades Conduta das crianças e Aplicação das histórias.

Essas recorrências são latentes no impresso, auxiliando na formação do aluno da escola religiosa com vistas às suas ações atuais e futuras. Dessa forma, a conduta entrelaçada com as Unidades gerais denominadas Lição de moral e Escolas paroquiais apontou para a formação e projeção da criança no futuro, mas atentando para os espaços que ela ocupava no presente. Se as leituras e mensagens de $O$ Pequeno Luterano tinham o objetivo de permear e controlar a conduta infantil, necessariamente seria preciso monitorar a infância, alertando para as implicações de ações que se refletiriam no futuro, como escolhas afetivas e profissionais.

Observa-se, assim, que as Histórias bíblicas e as Festas religiosas evidenciaram, do mesmo modo que as histórias de Lição de moral, uma relação numerosa de textos no cruzamento de dados. A presença de conteúdos da Bíblia em linguagem infantil é evidenciada em muitos momentos na apresentação gráfica da revista: há uma infinidade de imagens nessas histórias que pretendiam servir de modelo a ser seguido pelas crianças. Seria possível citar, nesse sentido, inúmeros exemplos de textos que apontam a necessidade de a criança ter confiança em Deus, apresentados por meio de histórias com personagens bíblicas.

Esses aspectos educativos presentes na aplicação de histórias se refletem nas orientações que a escola paroquial deveria adotar em relação à criança aluna/leitora/ cristã. A escola paroquial, na interlocução com a revista, orientada provavelmente pelos professores, compartilhava histórias que reforçavam a aplicabilidade de condutas desejáveis, como obediência e disciplina. Tais escolas eram sustentadas pelas paróquias das comunidades e podiam ser rurais, multisseriadas destinadas aos filhos dos colonos, ou urbanas a um público mais elitizado. Seria uma escola destinada à comunidade para a formação escolar geral, marcada por forte educação religiosa. Embora a revista O Pequeno Luterano não fosse um livro didático oficial, e sim material impresso para o público infantil, foi confirmado por depoimentos orais de professores e editores que ela era usada na escola paroquial tanto urbana quanto rural.

Seu conteúdo também reforçava a relação da escola com a religião e a doutrina. 0 texto transcrito a seguir menciona o engajamento das práticas infantis por meio do espelhamento no modelo cristão: 


\begin{abstract}
Jesus teu guia
Ao chegar este número do Pequeno Luterano às tuas mãos estarás em plena atividade escolar. Diariamente deves preparar e estudar as lições. Deves fazê-lo gostosamente e com prazer. Queres assim servir a Deus, agradar e obedecer aos pais, mestres e demais superiores e viver em paz e harmonia com os colegas, estas são virtudes de um coração crente. - Certamente queres ter estas virtudes e qualidades. Então, toma Jesus como teu guia. Imita-o na tua vida. Ele, na sua infância, aprendeu na escola os mandamentos de seu Pai Celestial. (O PEQUENO LUTERANO, 1965, p. 5).
\end{abstract}

Esse excerto pretende que o leitor relembre sua condição de aluno da escola paroquial, chamando atenção ao exemplo da infância de Cristo e orientando o leitor para que cumpra as suas obrigações e os seus deveres como cristão e como cidadão, incentivando-o, assim, a ter atitudes de docilidade e submissão. Embora o entrelaçamento entre esses dois campos - escola e igreja - se mostrasse acentuado nos textos da revista, na prática, as escolas paroquiais vinham perdendo espaço para as escolas públicas. ${ }^{21}$ Por isso, talvez a mensagem na revista em relação à educação escolar precisasse reforçar a importância do interesse pela Bíblia e pelo catecismo.

0 projeto da revista parece ter visado à projeção do futuro aluno/leitor/criança/cidadão. Esses diferentes modos de ser não vinham fragmentados, mas apareciam na projeção do futuro em elementos das mensagens da revista: no controle e na circunscrição da conduta infantil, bem como no uso das mensagens indutoras do modo de comportamento desejável.

A influência das escolas na manutenção do impresso é visível, como se pode verificar pelo excerto apresentado a seguir, o qual parece evidenciar, desde o título, a tensão e dependência da redação em relação aos seus leitores e ao universo escolar.

\begin{abstract}
Um apelo às escolas
Para ser atraente e interessante, nosso Pequeno Luterano precisa apresentar clichês, estampas, quadrinhos. Cada número devia ter bonita estampa na capa, tamanho maior, e umas três, de tamanho adequado nas outras folhas. Mas estes clichês que são feitos de chumbo e dos quais se tiram os quadros, custam ente 30 e 25 cruzeiros cada um. Se cada escola ajudasse com um donativo de Cr\$ 350,00 poderíamos mandar fazer uma porção de estampas e desta maneira tornar cada vez mais atraente o nosso Pequeno Luterano. Quem vai cooperar? Podeis enviar um vale postal para este endereço... [...] Se o Alfredinho e a Carmem tiverem um pai abastado que sozinho quer fazer uma oferta neste sentido naturalmente também será aceita. (MULLER, 1957, p. 2).
\end{abstract}

0 excerto em questão evidencia o uso da revista na escola, indicando que a ligação entre essas instituições (escola e igreja) deveria ser coesa e estreita, pelo menos nesse período. 0 fato de o periódico dirigir-se à escola para solicitar auxílio nas dificuldades demonstra que a instituição escolar exercia influência no comportamento dos assinantes, uma vez que, embora nem todos os alunos tivessem a assinatura, seu conteúdo era compartilhado com os alunos assinantes e não assinantes. ${ }^{22} \mathrm{~A}$ revista percebia que precisava ser mais

21- Segundo dados das Crônicas da Igreja (WARTH, 1979), o número de alunos paroquiais sofreu um decréscimo mais acentuado na década de 1960. Por isso, a instituição precisava investir em formas diferenciadas de educação das crianças.

22- Alguns alunos não eram assinantes, mas utilizavam a revista no espaço escolar por indicação dos professores. 
atrativa em seus aspectos gráficos, já que nesse período havia concorrência com outras revistas não religiosas e com revistas de confessionalidades diferentes. ${ }^{23}$

Os tensionamentos sofridos na circulação, na produção e na apropriação da revista são bem caracterizados em muitos textos, que apontam as dificuldades da revista, ao mesmo tempo em que corroboram a hipótese do seu uso nas escolas paroquiais, confirmando sua utilidade em atividades escolares para estimular e controlar a leitura das crianças. Assim, faz-se necessário haver Controle da leitura, Subunidade pouco recorrente, mas que explicita com clareza as estratégias dos editores. Isso pode ser observado no excerto a seguir, que enfatiza as formas de leitura e de valorização do impresso:

\section{O CANTO DO REDATOR}

LENDO O PEQUENO LUTERANO - Como é que você usa o Pequeno Luterano? Somente procura as charadas e suas respectivas respostas? Ou limita-se a olhar as estampas? Espero que não! Queremos, sim, trazer sempre figuras interessantes, mas a coisa principal do Pequeno Luterano são os artigos. Escrevemo-los para o bem de sua alma e de sua mente. Naturalmente não deve ser lido tudo duma vez. Não é preciso, leia um artigo na segunda-feira, outro na terça, outro na quarta, e assim por diante até que termine o periódico. Certas páginas você poderá usar para as suas devoções. (FLOR, 1960, p. 16).

0 modo da leitura é detalhado na revista, que explica a que se deve dar importância: ao conteúdo religioso. Além de ser usado como meio educativo escolar, as orientações de leitura também dariam suporte à formação religiosa. A sugestão da redação de espaçar o tempo entre uma leitura e outra poderia ter vários motivos, tais como aproveitar os artigos para realizar uma reflexão mais aprofundada do texto e ter a revista como leitura principal durante o mês todo. Mesmo a instituição tentando controlar a forma e o conteúdo das leituras das crianças, elas provavelmente não iriam seguir à risca tais indicações, detendo-se mais nas brincadeiras (como charadas e adivinhações) e nas imagens do que nos textos em forma de artigos sobre religião e conduta. Pode-se supor, assim, que tal tentativa de controle acontecia devido à preocupação do editor em criticar as crianças que atentavam somente aos aspectos lúdicos. Nesse sentido, o controle da leitura e o estímulo a ela estavam interligados.

Essas seriam algumas das muitas estratégias usadas pelos editores e redatores da instituição luterana. As táticas podiam estar implícitas, como a valorização das crianças em relação aos conteúdos lúdicos, sem que a revista tivesse de se deter de forma aprofundada nas mensagens de formação doutrinária.

Outro aspecto a ser observado consiste na Subunidade de Reclamações/pedidos, em que se evidenciam os descontentamentos dos leitores. Como já comentado, os redatores, por vezes, desculpavam-se e pediam aos leitores o incentivo às assinaturas, solicitando o envio de histórias e de cartas. Apelavam às escolas para que estas se engajassem no aumento das assinaturas, nas propostas de campanhas de redação e de arrecadação de fundos para os estudantes do seminário, entre outras práticas.

23- 0 controle da leitura infantil não era uma preocupação apenas de instituições religiosas, mas também de políticas governamentais e educativas que visavam coibir determinados livros ou revistas infantis. Para mais detalhes, ver Ventorini (2009). 
Em diferentes momentos da interlocução com os leitores, os textos chamam a atenção das crianças para a necessidade de colaborar com a revista, aceitá-la passivamente como recurso religioso e de formação moral e, assim, ajudar a redação a aumentar o número de assinantes. A estratégia não seria somente formar leitores, mas também engajá-los no projeto. Poder-se-ia afirmar que seria necessário, assim, engajar os meios educativos nesse projeto da revista. 0 texto a seguir, presente em uma das primeiras edições da revista em português, ilustra essa discussão:

\footnotetext{
Carta de Ano Novo

Com este número o nosso "Pequeno Luterano" entra no segundo ano de existência. Congratulome com os meus pequenos leitores por este grato ensejo e faço votos que o nosso jornalzinho tenha uma longa duração e que aqueles que o lêem e apreciam, aumentem numericamente. Quanto maior o número de assinantes, melhor para o nosso pequeno amigo. Por isso apelo aos meus pequenos leitores que façam o maior empenho possível da sua parte, para que aumente o número de leitores do "Pequeno Luterano". (HESSE, 1941, p. 7).
}

Esse fragmento do texto mostra como a redação estava conseguindo manter a revista. Ao longo do ano anterior, fora possível reorganizar a edição, adaptando-a à língua portuguesa, e, com isso, era necessário o aumento do número de assinantes, que poderia ocorrer a partir do apoio dos leitores. Essa era a estratégia usada quando a revista orientava os leitores e os conduzia a atender aos seus propósitos, podendo, por outro lado, consistir também na tática, a qual mostra a edição como dependente dos leitores para se manter, uma vez que solicita sua ajuda e colaboração.

Nesse sentido, por meio da demonstração de alguns conteúdos organizados pelo banco de dados, pode-se afirmar que a análise ora realizada, facilitada pela constituição metodológica, proporcionou uma efetiva problematização acerca dos diferentes usos da revista como fonte e objeto.

\section{Considerações finais}

Clarice Nunes (1992), há mais tempo, alertava os pesquisadores ao fato de que a inteligibilidade do texto histórico deriva das perguntas que o orientam. Nessa perspectiva, também documentos impressos por si só não conseguem mobilizar uma pesquisa, pois, para efetivá-la, é determinante que os conteúdos documentais sejam interrogados a partir de seu contexto, estabelecendo relações e interlocuções sob diferentes aspectos da problematização. Tais elementos, contudo, só se reverterão em reconhecida produção intelectual se houver um referencial teórico consistente aliado a um rigoroso procedimento analítico.

No caso aqui apresentado, devido à extensão de dados, foi necessário encontrar caminhos que permitissem a realização da pesquisa, motivo pelo qual o delineamento e a criação do banco de dados foram fundamentais. Como instrumento metodológico, o banco de dados organizou o trabalho por meio de aspectos quantitativos, possibilitando a execução de leituras sob a dimensão qualitativa da análise e destacando elementos representativos do impresso em questão. Como ferramenta operacional, auxiliou a 
analisar a riqueza em potencial que a revista $O$ Pequeno Luterano anunciava desde o início, permitindo construir categorias que, no decorrer do processo analítico, levaram não só a verificar recorrências, mas também a cruzar outros dados significativos.

Assim, foi possível perceber, por exemplo, o maior número de recorrências nos conteúdos doutrinários e religiosos que, ao serem relacionados com as Subunidades Conduta das crianças e Aplicação da história, levaram à compreensão da linha editorial básica da publicação: a necessidade da formação infantil voltada para um projeto do aluno/leitor/fiel futuro. A análise também permitiu entender que o referido impresso se fortaleceu no meio escolar, pelos conteúdos de interlocução com o leitor e pelos conteúdos de conhecimento geral, úteis aos procedimentos didáticos nas escolas paroquiais. Apesar de a revista não ser pensada como material didático, acabou legitimando-se nesse espaço.

De acordo com Michel de Certeau, táticas não têm lugar próprio, mas aproveitam o movimento da estratégia para se instaurar. Elas se distinguem nos "tipos de operações nesses espaços que as estratégias são capazes de produzir, mapear e impor, ao passo que as táticas só podem utilizá-los, manipular e alterar" (CERTEAU, 2011, p. 87). Nessa perspectiva, ao longo do processo analítico, foi mais difícil identificar as táticas dos leitores, já que se configuram como respostas que se engendram a partir do proposto pelas estratégias.

No caso da pesquisa aqui referida, é interessante destacar que as táticas estavam fortemente explicitadas em dados pouco recorrentes na revista. A Subunidade Reclamações/ pedidos é um exemplo dessa constatação. Tendo em vista o descontentamento dos leitores, que deixavam de assinar a revista, bem como os pedidos e as justificativas do editorial em relação aos problemas apresentados, foi possivel perceber a existência de alguns tensionamentos: o projeto da revista valorizava os textos doutrinários e orientava para a importância desse conteúdo na educação infantil; paradoxalmente, os leitores infantis, muitas vezes, consideravam os textos lúdicos como os de maior importância, tornando os demais secundarizados. Em outras palavras, os propósitos essenciais da linha editorial da revista, de quando em quando, eram desvirtuados pelos leitores, que, sem saber, valiam-se de determinadas táticas de apropriação do impresso que tinham diante de si.

Para finalizar, cabe dizer que as reflexões produzidas ao longo deste estudo só se consolidaram porque detalhes de análise foram fortemente facilitados pelo uso do banco de dados. Tal ferramenta, embora adaptada de um software e embora passasse por critérios subjetivos/objetivos dos pesquisadores envolvidos, proporcionou significativa visibilidade à dimensão quanti-qualitativa dos dados.

\section{Referências}

BASTOS, Maria Helena Câmara. Imprensa Pedagógica Rio-Grandense: CACIQUE - a revista da garotada gaúcha (1954-1963). Educação, Porto Alegre, v. 17, n. 27, p. 85-100, 1994.

BICCAS, Maurilene. 0 impresso como estratégia de formação: revista de Minas Gerais (1925-1940). Belo Horizonte: Argumenton, 2008. 
CERTEAU, Michel. A invenção do cotidiano: artes de fazer. 17. ed. Petrópolis: Vozes, 2011.

CHARTIER, Roger. À beira da falésia: a história entre incertezas e inquietude. Porto Alegre: UFRGS, 2002.

CHARTIER, Roger. A leitura: uma prática cultural. Debate entre Pierre Bourdieu e Roger Chartier. In: CHARTIER, Roger. Práticas de leitura. São Paulo: Estação Liberdade, 1996a. p. 231-254.

CHARTIER, Roger. Do livro à leitura. In: CHARTIER, Roger. Práticas de leitura. São Paulo: Estação Liberdade, 1996b. p. 77-106.

CHARTIER, Roger. El mundo como representación: estudios sobre historia cultural. Barcelona: Gedisa, 1996c.

CHARTIER, Roger. La revolucione de la cultura escrita. Barcelona: Gedisa, 2000.

CHARTIER, Roger. Textos, impressão, leituras. In: HUNT, Lynn. A nova história cultural. São Paulo: Martins Fontes, 1992. p. 211-238.

CORSETTI, Berenice. A análise documental no contexto da metodologia qualitativa: uma abordagem a partir da experiência de pesquisa do Programa de Pós-Graduação em Educação da Unisinos. Unirevista, São Leopoldo, v. 1, n. 1, p. 32-46, jan. 2006.

FISCHER, Beatriz T. Daudt. Professoras: histórias e discursos de um passado presente. Pelotas: Seiva, 2005.

FLOR, Marthin. 0 canto do redator. 0 Pequeno Luterano: Revista Oficial da Igreja Evangélica Luterana do Brasil, Porto Alegre, p. 16, maio/jun. 1960.

GAMBOA, Sílvio Sánchez; SANTOS FILHO, Jose Camilo (Org.). Pesquisa educacional: quantidade-qualidade. 5. ed. São Paulo: Cortez, 2002.

HESSE, Walther. Carta de ano novo. 0 Pequeno Luterano: Revista Oficial da Igreja Evangélica Luterana do Brasil, Porto Alegre, p. 7, jan./fev. 1941.

KUHLMANN JÚNIOR, Moisés; FERNANDES, Fabiana Silva. Construção de base de dados e análise historiográfica de propostas educacionais: um estudo sobre o parque infantil paulistano. (1947-1957). In: REUNIÃO ANUAL DA ANPED, 31., 2008, Caxambu. Anais... Caxambu: ANPED, 2008. p. 1-13.

LUCA, Tânia. Fontes impressas: história dos, nos e por meio dos periódicos. In: PINSKY, Carla Bassannezi (Org.). Fontes históricas. 2. ed. São Paulo: Contexto, 2010. p. 111-153.

MULLER, George. Um apelo às escolas. 0 Pequeno Luterano: Revista Oficial da Igreja Evangélica Luterana do Brasil, Porto Alegre, p. 2, fev./mar. 1957.

NUNES, Clarice. História da educação brasileira: novas abordagens para velhos objetos. Teoria \& Educação, Porto Alegre, n. 6, p. 6-15, 1992.

O PEQUENO LUTERANO: Revista Oficial da Igreja Evangélica Luterana do Brasil. Porto Alegre, jun. 1965. 
PESAVENTO, Sandra Jathaí. História e história cultural. 2. ed. Belo Horizonte: Autêntica, 2004.

PIRES, Alvaro. Sobre algumas questões epistemológicas de uma metodologia geral para as ciências sociais. In: POUPART, Jean et al. A pesquisa qualitativa: enfoques epistemológicos e metodológicos. 4. ed. Petropólis: Vozes, 2014. p. 43-94.

ROSA, Zita de Paula. 0 Tico-Tico: meio século de ação recreativa e pedagógica. Bragança Paulista: Edusf, 2002.

SCHWARTZMAN, Simon; BOMENY, Helena Maria B.; COSTA, Vanda Maria R. Tempos de Capanema. São Paulo: Edusp, 1984.

VENTORINI, Eliana. Regulação da leitura e da literatura infanto-juvenil no Rio Grande do Sul, na década de 1950: interdição, triagem e intervenção das autoridades. 2009. Dissertação (Mestrado) - Universidade Federal do Rio Grande do Sul, Porto Alegre, 2009.

WARTH, Carlos. Crônicas da Igreja: fatos históricos da Igreja Evangélica Luterana do Brasil: 1990-1974. Porto Alegre: Concórdia, 1979.

WEIDUSCHADT, Patrícia. A revista "0 Pequeno Luterano" e a formação educativa religiosa luterana no contexto pomerano em Pelotas - RS (1931-1966). 2012. Tese (Doutorado em Educação) - Universidade do Vale dos Sinos, São Leopoldo, 2012.

WEIDUSCHADT, Patrícia. Banco de dados e impressos: possibilidades de construção metodológica a partir da revista "O Pequeno Luterano". In: REUNIÃO NACIONAL DA ANPED, 37., 2015, Florianópolis. Anais... Florianópolis: UFSC, 2015. p. 1-20.

WEIDUSCHADT, Patrícia. 0 Sínodo de Missouri e a educação pomerana em Pelotas e São Lourenço do Sul nas primeiras décadas do século XX: identidade e cultura escolar. 2007. Dissertação (Mestrado em Educação) - Universidade Federal de Pelotas, Pelotas, 2007.

Recebido em: 24.10.2016

Revisões em: 25.04.2017 Aprovado em: 05.07.2017

Patrícia Weiduschadt é professora efetiva da Universidade Federal de Pelotas (UFPel), com doutorado em Educação pela Universidade do Vale dos Sinos (Unisinos).

Beatriz Teresinha Daudt Fischer é professora da Universidade do Vale dos Sinos (Unisinos), Campus Porto Alegre, com doutorado em Educação pela Universidade Federal do Rio Grande do Sul (UFRGS). 